\title{
A Transição do Cálculo para a Análise: uma resenha de três trabalhos de Márcia Maria Fusaro Pinto
}

PINTO, M. M. F. Entendendo Análise Real. In: SEMINÁRIO INTERNACIONAL DE PESQUISA EM EDUCAÇÃO MATEMÁTICA, 1., 2000, Serra Negra. Anais... Serra Negra: SBEM, 2000. p.153 - 158.

PINTO, M. M. F. Discutindo a Transição dos Cálculos para a Análise Real. In: LAUDARES, J. B.; LACHINI, J. A Prática Educativa sob o Olhar de Professores de Cálculo. Belo Horizonte: Fumarc, 2001. p. 123 - 145.

PINTO, M. M. F. Re-visitando uma Teoria: O Desenvolvimento Matemático de Estudantes em um Primeiro Curso de Análise Real. In: FROTA, M. C. R.; NASSER, L. Educação Matemática no Ensino Superior: Pesquisas e Debates. Recife: SBEM, 2009. Cap. 2, p. 27 - 42.

Por Sílvio César Otero-Garcia*

Apresentamos, nesta resenha, três trabalhos de Márcia Maria Fusaro Pinto $^{1}$ : dois capítulos de livro e um trabalho publicado em anais de eventos. Todos tratam, grosso modo, da problemática da transição do cálculo para a análise nos cursos de matemática. Para Pinto, o ensino do cálculo é fundamentalmente diferente do de análise, porque, enquanto nesse fundamentamse os princípios axiomáticos e sistemáticos, com definições formais, naquele são enfatizados aspectos computacionais e de manipulação simbólica, visando obter uma resposta final. Essa diferença acarretaria num grande impacto na transição do cálculo para a análise.

\footnotetext{
* Mestre em Educação Matemática. Universidade Estadual Paulista (UNESP), campus Rio Claro. Doutorando do Programa de Pós-graduação em Educação Matemática da Universidade Estadual Paulista (UNESP), campus Rio Claro, SP, Brasil. Endereço para correspondência: Avenida 24A, 1515, Bairro Bela Vista, CEP: 13.506-900. Rio Claro, SP, Brasil. E-mail: silvioce@gmail.com. ${ }^{1}$ Fusaro Pinto é graduada e mestre em Matemática pela UFMG e doutora em Educação Matemática pela University of Warwick. Foi professora na UFMG até 2009 e atualmente é professora adjunta na UFRJ.
} 
Em Pinto (2001), Discutindo a Transição dos Cálculos para a Análise Real, o foco não está na transição de que fala seu título, mas nas dificuldades apresentadas por diferentes alunos de uma disciplina de análise. A pesquisadora acompanhou o desenvolvimento de alunos durante seu primeiro contato com a matemática formal. De um modo mais geral, Pinto procurou observar algumas diferenças marcantes existentes entre a chamada matemática elementar, aquela vista na educação básica e até mesmo nos cursos de cálculo, e a matemática formal, quais sejam: a coerência, o descrever, o convencer versus a consequência, o definir, o provar. O referencial para coleta e análise dos dados seguiu a teoria do Advanced Mathematical Thinking Group e foi dividida em duas etapas. Na primeira delas, foi analisado um trabalho individual, escrito, de vinte estudantes de licenciatura em matemática e entrevistas com sete deles. Dessa etapa, a pesquisadora concluiu que poucos estudantes dominam a teoria formal da disciplina ao final do curso, sendo que a grande maioria constrói e fundamenta suas argumentações baseando-se somente em imagens. Na segunda etapa, onze bacharelandos e quatro licenciandos foram entrevistados e acompanhados em seus primeiros cursos de análise.

O percurso que Pinto tomou para analisar seus dados seguiu um processo de classificação/análise/classificação, no qual cada análise serve para reavaliar a classificação feita, acarretando uma nova análise, sucessivamente, até que uma estrutura natural emerja. Por meio desse processo, Pinto separou os estudantes em dois tipos, os que extraem significados (aceitam as novas regras do jogo; partem das definições formais dos conceitos e trabalham com as novas noções de prova) e os que atribuem significado (relacionam-se com as novas ideias por meio de suas experiências anteriores); e analisou neles três pontos: as definições, os argumentos e as imagens. As definições foram categorizadas em: descritivas, formais corretas ou formais distorcidas. Os argumentos: fundamentados na teoria formal ou fundamentados em experimentações mentais. As imagens: construídas a partir das definições ou não construídas a partir das definições. Dentre os onze bacharelandos que foram acompanhados e entrevistados, Pinto apresenta o caso de quatro. A pesquisadora também tece considerações sobre os licenciandos, porém sem trazer nenhum caso específico.

Ross, um aluno caracterizado dentre os que extraem significado, faz constante uso da memória, porém não de um modo mecânico. Segundo Pinto, a memória representa um papel importante no entendimento da matemática, sendo que, o que distingue os que de fato entendem dos que não, é a maneira como ela é mobilizada. As definições de Ross são majoritariamente simbólicas, com grande 
uso de representações verbais. Ele apresenta as definições corretamente. Com relação aos argumentos, baseia-se na teoria formal. Já suas imagens fazem uso de definições como critério para tomada de decisão. Rolf também é um estudante que extrai significado, mas, diferentemente de Ross, recorre à sua memória de modo mecanizado. Suas definições, argumentos e imagens são baseados na teoria formal que, entretanto, parecem compartimentalizadas, como parecem ser decorados os argumentos e distorcidas as imagens.

Chris, que atribui significado, faz constante uso de imagens visuais, esforça-se para não perder o contexto de vista em suas interpretações, a fim de tornar o conceito concreto. Para isso, vale-se de múltiplas representações. Suas definições são essencialmente descritivas e as argumentações baseiam-se na experimentação mental, que, no entanto, não é usada para provar afirmações, mas sim para atribuir significado para o conteúdo formal. Conclui sua argumentação em contexto formal. Já as suas imagens são construídas a partir das definições, revelando um processo de reconstrução de sua experiência prévia, o que explicita o conflito entre essa e o conhecimento novo. Cliff, assemelha-se a Chris, já que parece atribuir significado. Suas definições também são descritivas, entretanto os argumentos são fundamentados em imagens, que, por sua vez, não parecem ser construídas a partir da teoria formal.

Já os estudantes do curso de licenciatura, de modo geral, mostraram-se mais homogêneos: evitam o formalismo, suas definições são descritivas e seus argumentos baseados em imagens que não são construídas a partir da teoria formal. A prova matemática tem um tom de explicação, fundamentada em exemplos específicos. Para Pinto, o desempenho dos alunos desse grupo mostrou que devem ser discutidos aspectos relacionados à pertinência de um curso de análise nos currículos da licenciatura, bem como outros relacionados com a disposição desses alunos em acompanhar essa disciplina.

Por fim, destacamos a preocupação da pesquisadora com a opção que muitos alunos fazem de trocar o bacharelado pela licenciatura unicamente porque essa possui um número menor de disciplinas específicas que aquela; o que acaba contribuindo para que se mantenha uma cultura na qual a matemática é vista como ciência e disciplina exclusiva de poucos iluminados. Essa visão não contribui para a formação de nenhum dos dois tipos de profissionais. Relevante também, embora até seja parte do senso comum, é uma das conclusões de sua pesquisa: não existe fórmula ou engenharia única que possa conduzir o ensino da matemática avançada; os estudantes possuem suas próprias estratégias de aprendizagem e a elas se relacionam demandas cognitivas diferentes. Essa conclusão se 
contrapõe aos estudos que sugerem que o desenvolvimento de teorias formais sempre podem ser analisados sob o viés de processos mentais e representações simbólico-proposicionais.

Em Pinto (2009), a pesquisadora retoma e reinterpreta alguns de seus próprios resultados, notadamente aqueles referentes à transição do cálculo para a análise. Mais especificamente, com o objetivo de iniciar uma confrontação, são descritas as concepções de algumas pesquisas que tratam da produção de conhecimento por matemáticos profissionais e as estratégias de aprendizagem de estudantes de matemática avançada. Pinto abandona algumas terminologias, extraindo significado e atribuindo significado, por exemplo, são identificados como formal e natural.

Os relatos de Poincaré (1913) e MacLane (1994), apontam para duas estratégias de produção de conhecimento por matemáticos, a intuitiva e a formal. Já Burton (2002) traz três: a visual (figuras), a analítica (símbolos formais), e a conceitual (classificação de ideias). A maioria dos matemáticos articula, pelo menos, dois desses modos. Com relação às estratégias dos estudantes, Harel e Showder (1998) afirmam que os estudantes convencem a si mesmos e aos outros sobre a veracidade de resultados matemáticos usando esquemas de convicção externa, empíricos ou dedutivos. Para Weber e Alcock (2004), há só dois modos distintos de se apresentar uma prova matemática formal, o semântico e o sintático. No primeiro, o estudante é guiado em suas colocações por meio de representações dos objetos matemáticos para os quais a afirmativa se aplica. No segundo caso, a prova é formulada a partir de manipulações corretas das definições, de modo lógico e aceitável. Já Alcock e Simpson (2002, 2004, 2005) dividem em dois grupos os estudantes de matemática: os visualizadores e os não-visualizadores. Os visualizadores são aqueles que incluem imagens visuais em suas argumentações, o outro grupo, os que não. Os pesquisadores ainda falam do sentido de autoridade interno/externo, que trata das crenças que os alunos têm sobre seu papel na aprendizagem da matemática. Finalmente, Weber (2004) descreve o desempenho dos estudantes em três categorias: natural, formal e procedural.

Pinto confronta as ideias dos pesquisadores citados entre si, e também com as suas. Alcock e Simpson (2002, 2004, 2005) consideram que o uso de imagens visuais é um critério de categorização das estratégias dos estudantes. Para Pinto, a categorização feita por ela em sua tese é mais conveniente, visto que as imagens visuais podem ter muitos papéis na aprendizagem matemática, e não apenas o de referenciar desenvolvimentos simbólicos ou orientar a 
argumentação. Além disso, o papel descrito por Alcock e Simpson para as imagens visuais também pode ser exercido por outras representações, como as concepções espontâneas. Desse modo, a pesquisadora reforça sua escolha pelas denominações natural e formal, que podem ser identificadas, respectivamente, com o visual e não-visual de Alcock e Simpson.

Pinto segue explanando sobre outras diferenças e semelhanças entre suas categorias e a as demais apresentadas. Segundo a pesquisadora, o sentido de autoridade externa/interna de Alcock e Simpson (2002, 2004, 2005) é desenvolvido de modo diferente entre os alunos dos grupos formal (nãovisualizadores) e natural (visualizadores). Os estudantes do grupo formal reconhecem uma verdade matemática quando essa é estabelecida por meio de argumentação formal e simbólica (externa). Entretanto, muitas vezes não se sentem convencidos (internamente) dela. Para esses alunos, é importante desenvolver uma espécie de significado interno, do contrário, a construção da teoria matemática constituir-se-á como uma atividade procedimental e compartimentalizada. No caso do aluno Ross, esse significado interno deu-se através de uma produção sintática de prova. Esse exemplo se contrapõe à posição de Weber e Alcock (2004) de que provas sintáticas não são positivas no processo de ensino-aprendizagem da matemática formal. Os estudantes do grupo natural, por outro lado, parecem desenvolver uma convicção intuitiva interna. Para esses alunos, existe uma confiança na intuição, mesmo quando suas teorias não são consistentes com a apresentada pelo professor. O motivo dessa confiança viria das percepções desses estudantes, que são pautadas em experiências anteriores e significativas para eles. Apesar disso, não se pode dizer que tais estudantes não produzam conhecimento como os matemáticos; como um exemplo disso, Pinto cita Chris, que se relaciona com os conteúdos de uma forma natural e produz conhecimento de modo semântico.

Finalizando a identificação de suas categorias com as criadas pelos demais pesquisadores, Pinto fala das categorias de Weber (2004) com relação ao modo como os alunos aprendem a matemática formal. Além do natural e do formal, Weber admite uma terceira abordagem, a procedural. Para ela, no entanto, tal abordagem pode ser reconhecida como uma faixa de desempenho dentro da formal. A pesquisadora ressalta que existe um debate a respeito disso, e que Weber preferiu, então, considerar essa faixa à parte. Pinto destaca que o mais relevante no trabalho de Weber é a análise feita sobre os modos com que os estudantes se relacionam com a aprendizagem do conteúdo. Alcock e Simpson (2002, 2004, 2005) também tratam dessa questão. Os estudantes de análise 
costumam chegar ao curso com uma vivência considerável em matemática, desse modo, já terão estabelecido certas preferências com relação às representações dos conteúdos. Na maioria dos casos, os alunos na escola básica possuíam um ambiente de aprendizagem muito mais amplo quando comparado ao da universidade, onde se tem basicamente exposição no quadro negro. Entretanto, Pinto nos fala que os modos como os estudantes se relacionam com a aprendizagem do conteúdo se atualizam continuamente, assim sendo, podem ocorrer variações mediante a alteração de planejamento de um mesmo professor ou, quando os alunos, por exemplo, ao perceber seu fracasso inicial, recorrem à memorização ou a outras estratégias unicamente com o objetivo de serem aprovados.

Pinto, então, retoma os objetivos e resultados de suas pesquisas anteriores. Particularmente com relação à sua tese de doutorado, de 1998, conclui que a nova experiência matemática de um primeiro curso de análise implica diferentes respostas e relações com seus conteúdos por parte dos estudantes. As relações formal e natural podem ser caracterizadas em termos das definições, argumentos e imagens. Na relação de aprendizagem formal, os argumentos são construídos quase que exclusivamente por meio de representações verbais e algébricas, podendo ser caracterizados como predominantemente sintáticos. As definições, geralmente, são memorizadas, quer por uso reflexivo, quer por repetição. As imagens não obrigatoriamente provocam conflito, podendo simplesmente constituir uma compartimentalização de outras experiências matemáticas. Na relação de aprendizagem natural, os argumentos são orientados por representações geralmente não-verbais e por conceitos prévios envolvidos, podendo ser caracterizados como predominantemente semânticos. As imagens necessitam ser constantemente construídas. Pinto conclui, assim, que não existe um modo único e efetivo para apresentar a matemática formal ou para direcionar um percurso que objetive a produção de significado. As demandas cognitivas dos estudantes são muitas, de modo que o professor deve perceber outras estratégias e caminhos.

O terceiro trabalho que analisamos, Pinto (2000), é bastante breve se comparado aos demais. Nele há a análise que a pesquisadora fez das entrevistas com alunos e observações que das aulas de análise na Universidade de Warwick. Para isso, utiliza das mesmas abordagens e temas já descritos. Traz como exemplos os alunos Ross e Chris. Os resultados e discussões apresentados neste texto não têm novidade em relação aos que já relatamos. 


\section{Referências}

ALCOCK, L. J.; SIMPSON, A.P. Definitions: dealing with categories mathematically. For the Learnig of Mathematics, Fredericton, v. 22, n. 2, p. 28 - 34, July. 2002.

ALCOCK, L. J.; SIMPSON, A.P. Convergence of Sequences and Series. Education Studies in Mathematics, Dordrecht, v. 57, n. 1, p. 1 - 32, July. 2004.

ALCOCK, L. J.; SIMPSON, A.P. Convergence of Sequences and Series 2. Education Studies in Mathematics, Dordrecht, v. 58, n. 1, p. 157 - 175, Jan. 2005.

BURTON, L. Recognising Commonalities and Reconciling Differences in Mathematics Education. Educational Studies in Mathematics, Dordrecht, v. 50, n. 2, p. 157 - 175, Mar. 2002.

HAREL, G.; SOWDER, L. Students'Proof Schemes. In : DUBINSKY, E.; SCHOENFELD, A.; KAPUT, J. (Eds.). Research on Collegiate Mathematics Education. Providence, Ri: MAS, 1998. v. 3, p. 234 - 283.

MACLANE, S. Responses to Theoretical Mathematics. Bulletin of the American Mathematical Society, Providence, v. 30, n. 2, p. 190 - 193, Apr. 1994.

PINTO, M. M. F. Students' Understanding of Real Analysis. 1998, 320f. Tese (Doutorado em Educação Matemática) - University of Warwick, England, 1998.

POINCARÉ, H. Mathematics and Science: last essays. New York: Dover, 1913.

WEBER, K. Traditional Instruction in Advanced Mathematics Courses : a case study of on theather' leactures and proofs in an introductory real analysis course. The Journal of Mathematical Behavior, Amsterdã, v. 23, n. 2, p. 115 - 133, Apr. 2004.

WEBER, K.; ALCOCK, L.J. Semantic and Syntatic Proof Productions. Educational Studies in Mathematical, Dordrecht, v. 56, n. 2-3, p. 209 - 234, July. 2004. 
